\title{
Benefits of Environmental Management Systems in the Czech Republic
}

\author{
Jaroslava Hyršlová ${ }^{1}$, Miroslav Hájek ${ }^{2}$, and Gabriela Rajdlová ${ }^{2}$ \\ ${ }^{1}$ University of Economics and Management, Prague, Czech Republic \\ jaroslava.hyrslova@vsem.cz \\ ${ }^{2}$ Czech University of Life Sciences Prague, Czech Republic \\ hajekmir@volny.cz, g.rajdlova@seznam.cz
}

\begin{abstract}
Environmental Management Systems (EMS) are important voluntary tools used by the business sphere and other organisations in the world, as well as in the Czech Republic, for the management of the impacts of their activities, products and services on the environment. The article presents EMS as a tool for the management of the environmental aspects and impacts of organisations, depicts the development of their implementation into the practice deployed by organisations around the world and in the Czech Republic in the last 15 years and highlights the systems' benefits for the society and for the organisations themselves.
\end{abstract}

Keywords: Environment, environmental performance, environmental management, environmental management systems.

\section{Introduction}

A company's responsible approach to environment requires many changes. These have to include not only specific rectifying measures, usually of technical and/or technological nature, but primarily the entire management system in the company. Wider proactive corporate attempts at the integration of environment protection and sustainable development aspects into management systems were one of the most important factors of the environmental politics in the early 1990s. EMS have been formed and gained wide support from the corporate sphere. The aim of this article is to present EMS as a tool for the management of environmental aspects and impacts, to show the development of the implementation of EMS over the last 15 years both globally and in the Czech Republic, and most importantly to highlight the benefits of the system for companies.

\section{Implementation of EMS in the World and in CR}

EMS are being implemented around the world and in the Czech Republic both according to ISO 14001 and according to EMAS.

Figure 1 depicts development of the no. of certified organisations in the world and in Europe. As of the end of 2011, a total of 267,457 organisations held EMS 
certificates compliant with ISO 14001 ; this is $19 x$ more than at the end of 1999 . The highest increase in the number of certified organisations was registered in 2009 (up 34,400 , i.e. $18 \%$ on the total number of certified organisations registered as of December 31, 2008). In Europe, the certificate was held by a total of 106,700 organisations as of the end of 2011 (in 50 countries). The highest increase in the number of certified organisations in Europe was registered in 2010 (13,889 organisations). Europe is thus the no. 2 continent in the number of certificate holders.

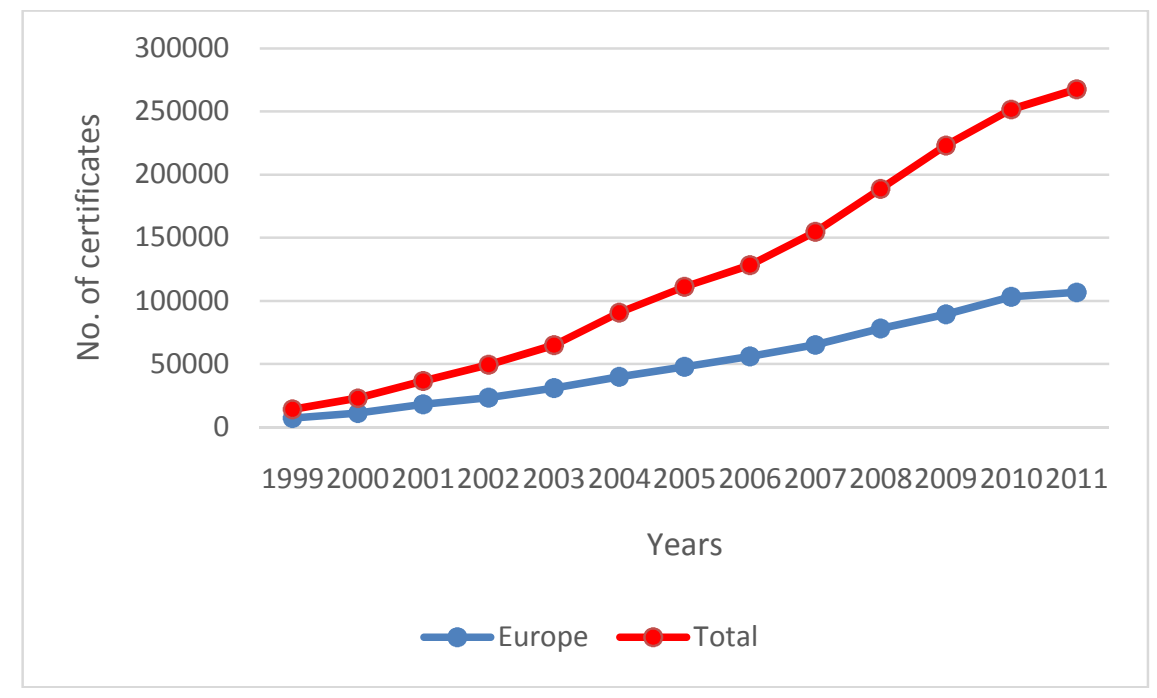

Fig. 1. Development of the no. of certified organisations in the world and in Europe in 1999-2011 (Source: [1])

In CR, the certificate was held by a total of 4,451 organisations as of the end of 2011. CR placed first among EU member states with comparable population. The highest increase in the no. of certified organisations was seen in 2010 (up 1,945, or $41 \%$ ).

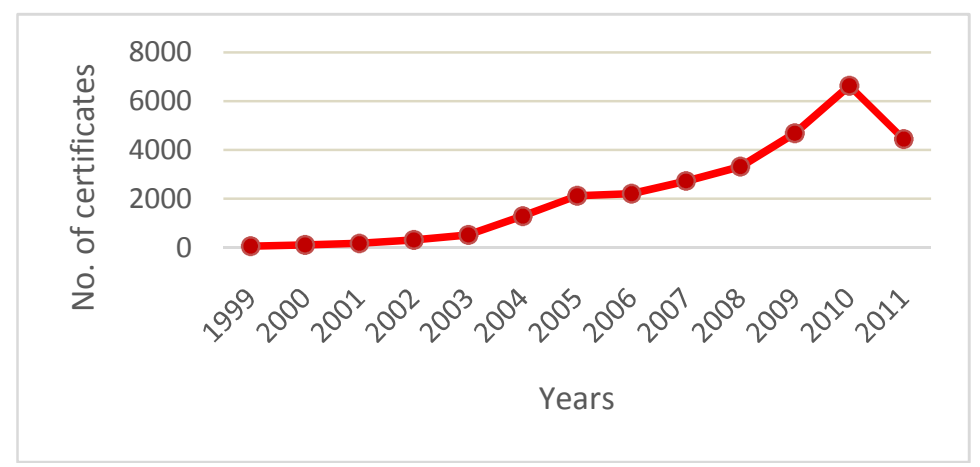

Fig. 2. Development of the no. of certified organisations in the Czech Republic in $1999-2011$ (Source: [1]) 
Massive growth was registered also in 2009 (the no. of certified organisations increased by 1,366, i.e. $41 \%$ ) and in 2005 (up 834 organisations, i.e. $165 \%$ ). Figure 2 depicts the development of the no. of certified organisations in the CR.

There were totally 4,581 organisations of various sizes and activity fields registered with the EMAS on the territory of the EU as of June 1, 2013. Italy $(1,652$ registrations) has the highest number of organisations registered with the EMAS, followed by Germany (1,283 registrations) and Spain (1,286 registrations) [2]. Figure 3 depicts development of the no. of registered organisations in the CR.

The previous text indicates that the number of certified and registered organisations has been growing significantly since 1999. The organisations clearly prefer to use systems built according to the internationally valid norm, ISO 14001 . The no. of certified organisations in the world is growing faster than in Europe. The Czech Republic is among the countries with a high number of certified organisations.

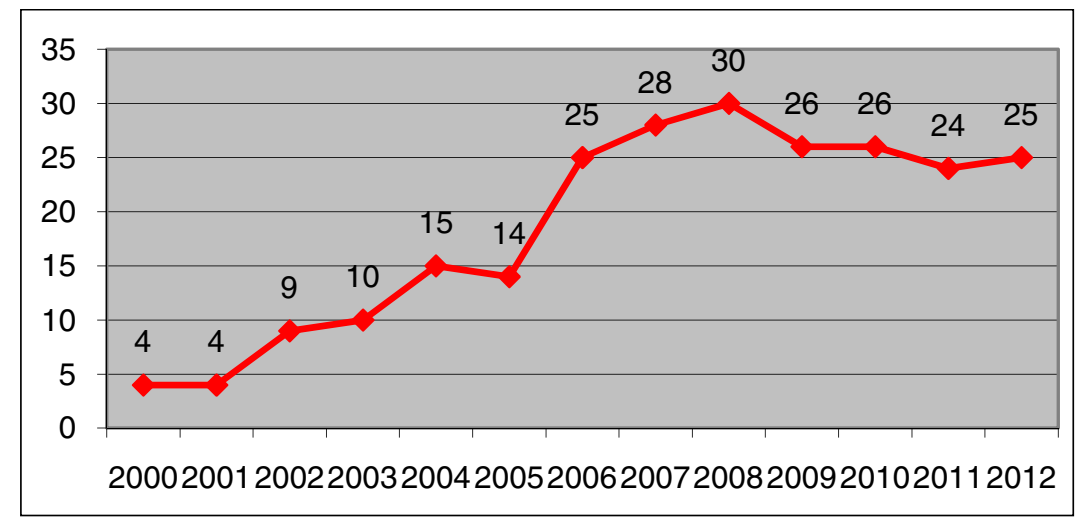

Fig. 3. Development of the no. of registered organisations in the Czech Republic in $2000-$ 2012 (Source: [3])

\section{Benefits of the Implementation of EMS in the Czech Republic}

The most recent extensive survey on the benefits of environmental management systems for the business sphere in the Czech Republic was carried out by the Czech Environmental Management Centre and the Czech Environmental Information Agency in $2005^{1}$. The survey used written questioning to find out primary information. Totally 1,265 organisations were polled, mostly companies that had EMS implemented at the time of the research. Filled questionnaires were returned by 224 companies (return rate of $17.7 \%$ ); out of this total, 222 organizations had implemented EMS. The reviewed

\footnotetext{
${ }^{1}$ The survey was carried out within the solution of research and development project no. VaV - 1C/4/13/04 (Application of Environmental Accounting on Macroeconomic and Microeconomic Levels). The project was financed by the Ministry of Environment. The co-author (J. Hyršlová) was the project's co-researcher.
} 
sample consisted primarily of large and medium companies ${ }^{2}$ with turnover exceeding CZK 100 mln p.a. Most strongly represented were organizations from the manufacturing industry (52\%) and construction industry (25\%). The reviewed companies had the system implemented predominantly acc. to ISO 14001 (of the total of 222 companies, $91 \%$ only held certificates acc. to ISO 14001, $6 \%$ held ISO 14001 certificates and simultaneously were registered with the EMAS program, while $3 \%$ had the system implemented, but not certified or registered). The importance of management systems for respondents was proven by the fact that $97 \%$ of the respondents had implemented also the ISO 9001 quality management system. Companies from both manufacturing industry and construction industry were registered in the EMAS program. The registered organizations ranged from large, medium and small enterprises to microcompanies.

The research resulted into the following basic findings [4]:

- The representatives of $92 \%$ of companies (from the total reviewed set) have confirmed that the organisation's management is dealing with environment protection issues. The share of respondents confirming that management is paying attention to the environmental performance regularly (the environmental performance is monitored and rated in regular intervals) grew with the companies' size. Employees were involved in the corporate environmental performance improvement process in all companies.

- $76 \%$ of companies carried out in the year preceding the survey (2004) measures within EMS that led to significant reduction of the consequences of corporate activities, products and/or services for the environment. This means that the companies were improving their environmental performance. According to the respondents, the implemented measures brought benefits also in other areas. $16 \%$ of the respondents have noted social benefits of these measures (primarily the benefit of improved working environment). Almost $14 \%$ of respondents have confirmed the economic benefits of the implemented environment protection measures, $13 \%$ of respondents perceived positive response from the public, business partners or public administration.

The representatives of companies of individual size categories (see Table 1) and individual sectors perceived the benefits of EMS differently.

The research has confirmed that companies viewed EMS as a tool for improving their environmental performance; large and medium enterprises and companies from the manufacturing industry perceived also the system's economic benefits. Half of the respondents pointed to the system's benefits for safety and health protection at work and improvement of working environment. Smaller companies that implemented EMS have not perceived the aforementioned benefits so unambiguously. They tended to point towards the importance of EMS for the improvement of relations with the public, business partners and state authorities (this benefit was most frequently stated also by representatives of the construction industry) and its benefit for higher knowledge potential.

\footnotetext{
${ }^{2}$ Classification of companies: micro-company $0-9$ employees; small company $10-49$ employees; medium company 50 - 249 employees; large company 249+employees.
} 
Table 1. EMS' benefits (acc. to company size) (Source: [4])

\begin{tabular}{|c|c|c|c|c|c|}
\hline \multirow[t]{2}{*}{ Type of benefit } & \multicolumn{5}{|c|}{$\begin{array}{l}\text { Relative rate (\% of respondents from the total no. of respondents in } \\
\text { the given category who have confirmed the benefit) }\end{array}$} \\
\hline & Reviewed set $(n=222)$ & Micro-firms & $\begin{array}{l}\text { Small } \\
\text { firms }\end{array}$ & $\begin{array}{l}\text { Medium } \\
\text { firms }\end{array}$ & $\begin{array}{l}\text { Large } \\
\text { firms }\end{array}$ \\
\hline $\begin{array}{l}\text { Improved environ- } \\
\text { mental performance }\end{array}$ & 74 & 45 & 62 & 72 & 88 \\
\hline Economic benefits & 59 & 27 & 55 & 58 & 68 \\
\hline Improved relations & 54 & 73 & 55 & 49 & 52 \\
\hline Benefits in social area & 51 & 55 & 51 & 57 & 45 \\
\hline Increased knowledge & 41 & 73 & 36 & 40 & 38 \\
\hline Provision of information & 27 & 55 & 26 & 30 & 19 \\
\hline
\end{tabular}

Another survey aimed to identify EMS' benefits for organisations was carried out in the Czech Republic in 2009. The survey used questionnaires and interviews. 3Totally 35 organisations that were registered with the EMAS program at the time of the research were polled. At the time when the research was carried out, mainly large and medium enterprises were registered with the EMAS program (63\% of the companies fell into the category of large enterprises, $23 \%$ into the category of medium enterprises); no micro-company was registered with EMAS. $63 \%$ of the registered companies were generating annual turnovers of over CZK 1 bln at the time of research. The no. of registered organisations increased most significantly in 2005 and 2006; the Czech Republic has thus received the European EMAS award for high increase in the no. of registered organisations. The increase in the no. of registered organisations may be attributed primarily to the changes to the building act; registration with the EMAS program became one of the mandatory criteria for participation in tenders. Totally 31 out of 35 polled organisations participated in the survey (return rate of $88.6 \%$ ).

The research brought the following basic results [5]:

- 28 respondents $(90 \%)$ were using an environmental management system that was simultaneously certified acc. to ISO 14001.

- More than half of the respondents have stated continuing the implementation of management systems into practice, efforts to boost the company's competitiveness and improvement of environmental performance as the main reason for registering the system.

- The systems' benefits, as perceived by organisations participating in the research, are stated in Table 2.

\footnotetext{
${ }^{3}$ The survey was carried out by the Institute of Chemical Technology, Prague. The article's authors use collected data and evaluates them in the context of this article's goal.
} 
Table 2. Systems' benefits (Source: [5]

\begin{tabular}{lcc}
\hline \multirow{2}{*}{ Systems' benefits } & \multicolumn{2}{c}{$\begin{array}{c}\text { Reviewed set } \\
\text { (n=31 organisations) }\end{array}$} \\
\cline { 2 - 3 } & Absolute rate & Relative rate \\
\hline $\begin{array}{l}\text { Improvement of environmental performance } \\
\text { (reduction of negative impacts) }\end{array}$ & 20 & $64 \%$ \\
$\begin{array}{l}\text { Improved image of organisation } \\
\text { Compliance with legislative norms on environ- } \\
\text { ment protection }\end{array}$ & 17 & $55 \%$ \\
$\begin{array}{l}\text { Management system improvement (links to ISO } \\
\text { 9000, ISO 14001) }\end{array}$ & 10 & $32 \%$ \\
$\begin{array}{l}\text { Increased competitiveness } \\
\text { Improved supplier-customer relations }\end{array}$ & 9 & $29 \%$ \\
Reduced costs of raw materials and energies & 3 & $10 \%$ \\
Better negotiation with banks and insurers & 3 & $10 \%$ \\
\hline
\end{tabular}

More than half of the respondents viewed the system's contribution to the improvement of the organisation's environmental performance and improvement of image as the main benefits. According to the opinion of one third of respondents, the system contributes towards compliance with legislative norms on environment protection and generally improves the quality of the organisation's management system.

- 8 respondents $(26 \%)$ described the system as an important tool for environment protection; 17 respondents $(55 \%)$ regarded the system as a formal instrument that brought order into the organisation. 6 respondents $(19 \%)$ have stated that EMAS failed to meet their expectations in all sectors that motivated them to implement the system. Two respondents have confirmed that their organisation does not plan to maintain EMAS for this reason.

Following up on the research carried out in 2009, the corresponding survey was held also in 2013. At the time of the research, 24 organisations were registered in the EMAS program at the time of research. Large companies dominated among registered organisations (12 organisations, i.e. $50 \%$ ), followed by medium companies (9 organisations, i.e. $37.5 \%$ ); no micro-company has registered with the EMAS program yet. Two municipal authorities and one regional authority have registered the system. All registered organisations (except for municipalities and the regional authority) generated turnover of over CZK 1 bln last year. Half of the registered organisations are doing business in construction industry. All organisations were asked to take part in a survey based on questionnaire enquiries. Filled questionnaires were returned by 21 organisations (return rate of $87.5 \%$ ). The survey resulted into the following findings: 
- 13 respondents (62\%) have confirmed that the company's environmental performance influences the success of their business also under current conditions and in the current business environment. 4 respondents $(19 \%)$ have stated that the environmental performance is not unambiguously directly linked to the success of their business.

- All organisations participating in the research (with the exception of the regional authority) have the environmental management system certified also acc. to the ISO 14001 norm. The evaluated companies have first implemented the system in compliance with the requirements of the ISO 14001 norm and then gained the EMAS registration (the evaluated companies gained the first certificates already in 1998, the highest no. of certificates was awarded in 2005; the companies gained first registrations in 2004, the highest increase in the no. of registered companies was reported in 2005 and 2006).

- The respondents have confirmed the following main reasons for registering with the EMAS program: efforts at raising (or maintaining) the company's competitiveness (52\% of respondents) and improvement of image and raising of the organisation's credibility (43\% of respondents).

- The research focused primarily on the systems' main benefits. The overall results are summarized in Table 3.

Table 3. Systems' benefits

\begin{tabular}{lcc}
\hline \multirow{2}{*}{ Systems' benefits } & \multicolumn{2}{c}{$\begin{array}{c}\text { Reviewed set } \\
(\mathrm{n}=21 \text { organisations) }\end{array}$} \\
\cline { 2 - 3 } Improvement of environ. performance & Absolute rate & Relative rate \\
\cline { 2 - 3 } Compliance with legislative norms & 16 & $76 \%$ \\
Increased competitiveness & 9 & $43 \%$ \\
Improved image of organisation & 8 & $38 \%$ \\
Better preparedness for accidents & 5 & $24 \%$ \\
Creating environmental awareness in employees & 5 & $24 \%$ \\
Overview of operating documentation & 5 & $24 \%$ \\
Improved communication & 4 & $19 \%$ \\
Reduced costs of raw materials and energies & 4 & $19 \%$ \\
Improved supplier-customer relations & 3 & $14 \%$ \\
Better intra-company organisation and man- & 2 & $9 \%$ \\
agement & 2 & $9 \%$ \\
\hline
\end{tabular}

The respondents have stated the improvement of their corporate environmental performance $(76 \%)$ as the main benefit of the system. According to the respondents' 
opinion, the system also contributes to the compliance with legislative norms on environment protection and the company's competitiveness. 3 respondents have described the system as a solely formal matter; they think that the system has no direct link to the company's environmental performance.

- 8 respondents (38\%) view EMS as an important tool for environment protection; 9 respondents $(43 \%)$ perceive the system as a formal instrument contributing to order in the organisation. 12 respondents $(57 \%)$ think that the systems' benefits exceeds the implementation and maintenance costs. All respondents have confirmed that they plan to continue maintaining and recertifying the systems acc. to ISO 14 001. 3 respondents are analysing whether they will register the system with EMAS again. The main reason for not registering the system with the EMAS program for them is the high registration costs.

\section{Conclusions}

The benefits of EMS may generally be perceived on environmental, economic, social and organisational level (this classification of benefits is stated e.g. in [6]).

In early 21 st century the companies doing business in the territory of the Czech Republic that had implemented the environmental management system perceived the system as an instrument for the management of the environmental impacts of corporate activities, products and services. Some of the companies (predominantly large and medium enterprises and firms from the manufacturing industry) were also aware of the systems' economic benefits. Part of the companies from the manufacturing industry pointed also to the systems' benefits for safety and health protection at work and improvement of the working environment. The companies clearly prefer to implement the systems in line with the requirements of ISO 14001 and want to maintain the implemented and certified systems in the long run.

From mid-1990s onwards, some companies, primarily large and medium enterprises, began to register their environmental management systems also with the EMAS program. Registration with the program was a logical extension for the system that complies with the requirements of the ISO 14001 norm. The registration process was joined primarily by large companies from the construction industry, as registration with the EMAS program was an important step towards remaining competitive in public tenders.

The reasons for registration with the EMAS program in the monitored group changed over the monitored period (2009-2013). In 2009, the companies stated continuing with the implementation of management systems and efforts at raising (or maintaining) competitiveness as the main reason. The foreseen benefits for the company's environmental performance (environmental benefits) dominated in the overall listing of reasons. In 2013, the companies accent primarily the economic reasons for registration with the EMAS program - efforts at maintaining or boosting competitiveness.

In 2009, the monitored group of companies perceived the improvement of the organisation's environmental performance and image as the main benefits of registration 
with the EMAS program. Environmental benefits dominated the overall list of benefits for companies; the organisations were also aware of the impact of the registration on their higher credibility. The survey held in 2013 confirmed the systems' environmental benefits, i.e. their importance for the management and improvement of the environmental performance and compliance with legislative norms on environment protection. Companies continue to perceive the systems' economic benefits, i.e. their contribution towards the maintenance and/or boosting of competitiveness. To a lesser extent, the enterprises note also social benefits (creating environmental awareness in employees) and organisational benefits (overview of operating norms and documentations).

The total no. of organisations registering with the EMAS program has dropped in the monitored period (2009-2013). Future will show whether new organisations will be interested in entering the registration process and whether existing organisations will be interested in renewing their registrations.

To achieve all benefits of EMS, it is necessary to ensure that EMS is not just a formal tool; environmental aspects have to be implemented into the entire corporate management system and reported to stakeholders (see e.g. [7]). The goal is to secure the achievement of corporate goals for economic performance, environmental performance as well as social aspects of doing business.

\section{References}

1. The ISO Survey of Management System Standard Certifications (1999-2011), http: //www.iso.org

2. EMAS Register, http://www. emas-register.eu

3. Ministry of the Environment of the Czech Republic, http://www . mzp.cz

4. Hyršlová, J., Mísařová, P.: Udržitelný rozvoj a systémy environmentálního managementu v ČR. Planeta, XV (2), 3-6 (2007)

5. Dobrý, J.: Analýza významu a postavení EMAS v České republice a Evropské unii jako nástroje ochrany životního prostředí. VŠCHT, Praha (2010)

6. Kreuz, J., Vojáček, O.: Firma a životní prostředí. Oeconomica, Praha (2007)

7. Hodinka, M., Štencl, M., Hřebíček, J., Trenz, O.: Current Trends of Corporate Performance Reporting Tools and Methodology Design of Multifactor Measurement of Company Overall Performance. Acta Univ.Agric. et Silvic. 60(2), 85-90 (2012) 